\title{
Asymmetric foreign exchange exposure: a sector analysis
}

\author{
$\underline{\text { L.K. Lim }}^{\mathrm{a}}$ \\ ${ }^{a}$ School of Accounting, Finance and Economics, Edith Cowan University, Perth \\ Email:1.limt@ecu.edu.au
}

\begin{abstract}
Standard finance theory argues that changes in exchange rate carry transaction and economic exposures on a firm's expected future cash flows, which in turn affect the firm value. An extension of the theory further suggests that the foreign exchange effect may also be asymmetric. Although numerous empirical studies have attempted to detect the sensitivity of stock returns to exchange rate changes, conclusive evidence is far and between. The overall mixed findings in the literature could in part due to two specification problems, namely omission of relevant factors proposed by several theories and the presence of conditional heteroscedasticity in share price and exchange rate changes. Most studies on currency risk focus on major industrialized countries, such as Canada, France, Germany, Japan, the United Kingdom and the United States (US). A few studies across Asia Pacific have limited their investigation on firms or industries in a single country and examine only the exposure to the US dollar.
\end{abstract}

Recent global financial crisis of 2007-2009 and fears of a sovereign debt crisis in some European countries have resulted in more volatile stock markets and exchange rate movements. This study aims to re-evaluate whether more volatile exchange rate movement has asymmetrically affected returns on the Australian stock market. Given that China, Japan and the European Union have overtaken the United States as Australia's top three trading partners in recent years, these currencies would have significant impact on its stock market. Using weekly data, this study examines exposure to the Chinese yuan, the Japanse yen, the European euro, the US dollar and the trade-weighted index on the market and sector returns in Australia from January 1990 to June 2011. The generalised autoregressive conditional heteroscedasticity model is used to overcome the problem of conditional heteroskedasticity in price changes.

The empirical results suggest significant exchange rate effects on Australian market returns for all five exchange rate series with asymmetric exposure to the Chinese yuan. At the sector level, domestic market return is found to have more significant influence than exchange rate risk on all sector returns. Of all 10 sectors, the four sectors that do not have any exchange rate exposure are Consumer Goods, Technology, Telecommunication and Utilities. The six sectors that have significant asymmetric exposure to at least one currency are Basic Materials, Consumer Services, Financials, Health Care, Industrials, and Oil \& Gas. Of the six sectors, Basic Materials would benefit from the appreciation of the Australian dollar while the other five sectors would benefit from the depreciation of domestic currency. The results also suggest the Chinese yuan exposure on the sector returns has increased in recent years.

Keywords: Exchange rate, asymmetric exposure, conditional heteroscedasticity, sector return 


\section{INTRODUCTION}

The subject of exchange rate exposure has long been of interest to academic researchers. Standard finance theory argues that changes in exchange rate carry transaction and economic exposures on a firm's expected future cash flows, which in turn affect the firm value. An extension of the theory further suggests that the foreign exchange effect may also be asymmetric. Sources of the asymmetric exposures include pricing to market behaviour (Froot and Klemperer, 1989; Marston, 1990; Knetter, 1994), hysteresis (Ljungqvist, 1994; Christophe, 1997), and asymmetric hedging (Booth, 1996).

Although numerous empirical studies have attempted to detect the sensitivity of stock returns to exchange rate changes, conclusive evidence is far and between. For example, studies that focus on the U.S. firms (see Jorion, 1990, 1991; Bodnar and Gentry, 1993; Bartov and Bodnar, 1994; and Griffin and Stulz, 2001) report few firms or industries exhibit significant exchange rate exposures. In another front, Allayannis (1996) and Chow et al. (1997) find that exchange rate exposure becomes more significant at the longer return intervals, whereas Chamberlain et al. (1997) and Di Iorio and Faff (2000) document greater foreign exchange sensitivity using daily rather than monthly data.

The overall mixed findings in the literature could in part due to two specification problems as suggested by Koutmos and Martin (2003). First, in light of the several known theories mentioned earlier that argue for the asymmetric currency exposure, failure to incorporate such effect may result in model misspecification and could cast doubt on the outcome of an empirical finding. Second, in the presence of conditional heteroskedasticity, the violation of independent and identically distributed assumption could lead to inefficient estimates and bias the test statistics. In fact, both Baillie and Bollerslev (1989) and Hsieh (1989) report nonnormal and time-dependent second moment in the foreign exchange market data. By using autoregressive conditional heteroscedasticity (ARCH) and generalised autoregressive conditional heteroscedasticity (GARCH) models, they are able to remove all heteroskedasticity in price changes in the currencies examined.

Most studies (see Jorion, 1991; Griffin and Stulz, 2001; Kuoutmos and Martin, 2003) on currency risk also focus their study on major industrialized countries, such as Canada, France, Germany, Japan, the United Kingdom and the United States (US). A few studies across Asia Pacific have limited their investigation on firms or industries in a single country. For instance, Marston (1990) and $\mathrm{He}$ and $\mathrm{Ng}$ (1998) examine the sensitivity of Japanese firms to exchange rate risk, while Khoo (1994) and Di Iorio and Faff (2000) estimate foreign currency exposure at the firm and industry levels in Australia, respectively. Similarly, Chang (2002) focus his investigation on the currency risk at industry level in Taiwan around the Asian financial crisis. Firms in the Asia Pacific region tend to be very export oriented and often with the US as their largest export market so these studies examine only the exposure to the US dollar.

Recent global financial crisis (GFC) of 2007-2009 and fears of a sovereign debt crisis in some European countries have resulted in more volatile stock markets and exchange rate movements. Changes in the exchange rate may carry significant impact on firms' subsequent cash flows and therefore is of practical important to investors and finance managers interested in the area. This study aims to re-evaluate whether more volatile exchange rate movement has asymmetrically affected returns on the Australian stock market. Given that China, Japan and the European Union have overtaken the US as Australia's top three trading partners in recent years, this paper investigates the exposure of these currencies on the market and sector returns in Australia. The two features proposed by Koutmos and Martin (2003) have also been incorporated into the model and test specification. The rest of the paper is organized as follows. Section 2 describes the data and the methodology. Section 3 reports the empirical findings of the exchange rate effect on sector returns in the sampled countries. The last section concludes the paper.

\section{DATA AND METHODOLOGY}

The weekly total market return and sector indices for Australia stock market and the exchange rate series are obtained from DATASTREAM over the period from January 1990 to June 2011. These market and sector return indices have been adjusted for dividends. The 10 sector indices included in this study are Basic Materials, Consumer Goods, Consumer Services, Health Care, Financials, Industrials, Oil \& Gas, Technology, Telecommunication, and Utilities. The weekly market returns, sector returns and exchange rate changes are calculated from the first difference of the logarithm of the series. The full sample period consists of 1122 observations are available for the total market return and seven sector returns. The three sectors that have short sample periods are Oil \& Gas from June 2000 to June 2011 (576 observations), Technology from May 2001 to June 2011 (529 observations) and Telecommunication from June 1996 to June 2011 (787 observations). 
In analyzing the foreign exchange rate exposure, it is important to examine the currencies of Australia's major trading partners, namely China, Japan, members of European Union and the United States. A tradeweighted index ${ }^{1}$ (TWI) is also included in the study given that it reflects the importance of Australia's major trading partners which based on both merchandise and services trade. The four currencies, namely the Chinese yuan (CHY), the Japanese yen (JPY), the European euro and the US dollar (USD), are expressed in the unit of foreign currency per Australian dollar (AUD). Data on the European euro is only available from January 1999 to June 2011 (652 observations).

Table 1: Summary Statistics for Weekly Market Returns, Exchange Rate Changes and Sector Returns for Australia (\%)

\begin{tabular}{lcccccc}
\hline Country & Obs. & Mean & Std Dev & Skewness & Kurtosis & Jarque-Bera \\
\hline Exchange rate changes & & & & & & \\
\multicolumn{1}{c}{ Chinese yuan } & 1122 & 0.0549 & 2.0917 & 6.3980 & 146.9381 & $976229.2^{*}$ \\
European euro & 652 & 0.0545 & 1.6361 & -1.0301 & 12.8982 & $2776.93^{*}$ \\
Japanese yen & 1122 & -0.0240 & 2.3439 & -1.4594 & 17.3923 & $10081.98^{*}$ \\
US dollar & 1122 & 0.0270 & 1.6782 & -1.2374 & 15.6243 & $7737.02^{*}$ \\
$\begin{array}{l}\text { Trade weighted } \\
\text { index }\end{array}$ & 1122 & 0.0213 & 1.4823 & -1.4915 & 17.9083 & $10806.44^{*}$ \\
Market return & 1122 & 0.1860 & 2.1207 & -0.3288 & 5.4996 & $312.31^{*}$ \\
Sector returns & & & & & & \\
Basic Materials & 1122 & 0.2464 & 2.9045 & -0.2247 & 6.8630 & $707.08^{*}$ \\
Consumer Goods & 1122 & 0.0824 & 3.2942 & -1.1115 & 12.6802 & $4611.77^{*}$ \\
Consumer Services & 1122 & 0.1868 & 2.6408 & -0.4022 & 6.9651 & $765.26^{*}$ \\
Financials & 1122 & 0.2093 & 2.3533 & -0.3573 & 5.9964 & $443.62^{*}$ \\
Health Care & 1122 & 0.1723 & 2.2947 & -0.2450 & 5.1983 & $237.15^{*}$ \\
Industrials & 1122 & 0.0865 & 2.4931 & -0.2652 & 4.3282 & $95.62^{*}$ \\
Oil \& Gas & 576 & 0.4037 & 4.2051 & -0.6485 & 6.6824 & $365.82^{*}$ \\
Technology & 529 & 0.2395 & 5.2733 & -1.3430 & 14.808 & $3232.47^{*}$ \\
Telecommunication & 787 & 0.1679 & 3.7965 & 1.4913 & 17.6302 & $7310.56^{*}$ \\
Utilities & 1122 & 0.2858 & 2.8874 & 0.2456 & 4.6167 & $133.46^{*}$ \\
\hline & & & & & & \\
\hline
\end{tabular}

The summary statistics of the weekly exchange rate changes, market returns and sector returns are presented in Table 1. On average, the Australian dollar has appreciated against the currencies of its major trading partners except for the Japanese yen. The return distribution in the Australian market show high nonnormality, highlighted by its skewness and kurtosis. Based on the Jarque-Bera (1980) test (see Table 1), the non-normality for the market and sector return series are significant at the $1 \%$ level. The preliminary result is therefore consistent with Bollerslev et al. (1992) that the return series are conditional heteroskedasticity.

\footnotetext{
${ }^{1}$ The base level for the trade-weighted index was set at 100 in May 1970. There are 21 currencies included in the index for 2010/11 which account for 93\% of Australia's merchandise trade. The top four currencies in the TWI are the Chinese yuan, the Japanese yen, the European euro and the US dollar which account for 22.54\%, $14.94 \%, 9.92 \%$ and $8.54 \%$ of the weights, respectively (RBA, 2011).
} 
Specifically, the evidence suggests that stock returns have time-varying volatility, and error terms from ordinary least square regressions involving stock returns are also not normally distributed. To incorporate heteroscedasticity and to distinguish between nonnormal conditional and unconditional errors, the GARCH model developed by Bollerslev (1986) is used to examine the exchange rate risk exposure.

For the GARCH $(1,1)$ model where the variance term depends only upon last period's variance and squared residual, the conditional variance of the unconditional shock $\varepsilon_{t}$ is given by

$$
\begin{aligned}
\varepsilon_{t} & =\eta_{t} \sqrt{h_{t}} \\
h_{t} & =\omega+\alpha \varepsilon_{t-1}^{2}+\beta h_{t-1}
\end{aligned}
$$

where $\eta_{t}$ is a sequence of normally, independently and identically distributed random variables with zero mean and unit variance, $\omega>0, \alpha>0$, and $\beta \geq 0$. The estimates of the parameters of GARCH model are derived using the Gauss-Newton/BHHH (Berndt, Hall, Hall and Hausman) algorithm (Berndt el at., 1974).

To test the asymmetric foreign exchange exposure, we use the augmented market model proposed by Koutmos and Martin (2003). In its testable form at the market and sector level,

$$
\begin{aligned}
R_{m, t} & =\beta_{0}+\left(\beta_{x}+\beta_{D, x} D_{t}\right) x_{t}+\varepsilon_{t} \\
R_{s, t} & =\beta_{0}+\beta_{1} R_{m, t}+\left(\beta_{x}+\beta_{D, x} D_{t}\right) x_{t}+\varepsilon_{t}
\end{aligned}
$$

where $R_{m, t}$ is the market return at time $t, R_{s, t}$ is the sector index return, $x_{t}$ is the unanticipated exchange rate change, $D_{t}$ is a dummy variable which takes the value of one if $x_{t}<0$ and zero otherwise, and $\varepsilon_{t}$ is the error term with zero mean and constant variance. For both Equations (3) and (4), $\theta=\left(\beta_{x}+\beta_{D x} D_{t}\right)$ measures exposure to exchange rate movements and is decomposed into its positive and negative components, where $\beta_{x}=\theta^{+}$and $\beta_{D x}=\left(\theta^{+}-\theta^{-}\right)$to test for asymmetry exposure. A statistically significant $\beta_{D, x}$ implies the exchange rate exposure is asymmetric.

To estimate the unanticipated exchange rate change, $x_{t}$, the exchange rate changes are assumed to follow a discrete lognormal diffusion process,

$$
\ln S_{t}=\mu+\ln S_{t-1}+x_{t}
$$

where $S_{t}$ is the spot exchange rate and $x_{t}$ is the unanticipated exchange rate change or innovation. The lognormal diffusion process in Equation (5) therefore is also a representation that the level of exchange rate follows a random walk. Since the drift term, $\mu$, is found to be approximately zero in daily and weekly frequencies (Meese and Rogoff, 1983), the unanticipated exchange rate change, $x_{t}$, is simply the log-different of the exchange rate.

Unit root tests are conducted to investigate whether each of the five logarithmic exchange rate series follows a random walk. Both the Augmented Dicky-Fuller (Dickey and Fuller, 1981) and the Phillips-Perron (Phillips and Perron, 1988) tests fail to reject nonstationarity of all five series in level. However, both test statistics for all five series in first-difference are significant at the $1 \%$ level, which indicate the transformed series are stationary. Evidence of a unit root at the level of each exchange rate therefore supports the expected exchange rate formation process in Equation (5).

\section{EMPIRICAL FINDINGS}

All estimation and test results of the GARCH $(1,1)$ model are derived using the EViews 7.1 software. Table 2 presents the maximum likelihood estimates of exposure to five exchange rates at the market level. Apart from asymmetric exposure to the Chinese yuan, the Australian market exhibits statistically significant symmetric exposure to the other currencies at the $5 \%$ level. Significant positive coefficients indicate that the Australian market returns benefit from an appreciation of domestic currency against its trading partners in the last two decades. It is evident from the variance equation estimates that the error terms are conditionally heteroskedasticity. The sum of $\alpha+\beta$ for each currency exposure is close to unity which indicate the variance process or the impact of a shock is highly persistence.

A summary of significant exposure and asymmetric exposure to five exchange rates for all 10 sectors are given in Table 3. Overall, the effect of different exchange rate on individual sector return is mixed. Of all 10 sectors, the four sectors that do not have any exchange rate exposure are Consumer Goods, Technology, 
Telecommunication and Utilities. There are evidence of asymmetric exposure to at least one currency for six sectors, namely Basic Materials, Consumer services, Financials, Industrials, Health Care and Oil \& Gas. With the backdrop of the 2007-2009 GFC and the European debt woes, the foreign currency exposure is also estimated over the period from January 2006 to June 2011. As shown in Table 3, the results indicate more sectors are experiencing asymmetric exposure to the Chinese yuan in the last five years. This could be attributed to the increased merchandise trade between Australia and China in recent years.

Table 2: Exchange Rate Exposure at the Market Level (January 1990 - June 2011)

\begin{tabular}{lcccccc}
\hline & & \multicolumn{2}{c}{ Conditional Mean } & \multicolumn{2}{c}{ Conditional Variance } & \\
\cline { 4 - 6 } Currency & Obs. & \multicolumn{1}{c}{$\beta_{x}$} & $\beta_{D, x}$ & $\alpha$ & $\beta$ & Adj. $R^{2}$ \\
\hline Chinese yuan & 1122 & $0.1251^{*}$ & $0.2982^{*}$ & $0.0674^{*}$ & $0.9010^{*}$ & 0.1035 \\
European euro & 652 & $0.4000^{*}$ & -0.0843 & $0.0848^{*}$ & $0.8881^{*}$ & 0.1321 \\
Japanese yen & 1122 & $0.2851^{*}$ & -0.0655 & $0.0538^{*}$ & $0.9199^{*}$ & 0.1073 \\
US dollar & 1122 & $0.3624^{*}$ & -0.0125 & $0.0699^{*}$ & $0.8928^{*}$ & 0.1137 \\
$\begin{array}{l}\text { Trade-weighted } \\
\text { index }\end{array}$ & 1122 & $0.3771^{*}$ & 0.0163 & $0.0619^{*}$ & $0.9068^{*}$ & 0.1054 \\
\hline
\end{tabular}

Notes: The sample period for the European euro is shorter, i.e. January 1999 - June 2011.

$*$ denotes significant at the $5 \%$ level.

Table 3: Summary of Exchange Rate Exposure for Sector Indices

\begin{tabular}{|l|ccccc|ccccc|}
\hline & \multicolumn{4}{|c|}{ January $1990-$ June 2011 } & \multicolumn{5}{c|}{ January 2006- June 2011 } \\
\cline { 2 - 7 } Sector & CHY & JPY & USD & Euro & TWI & CHY & JPY & USD & Euro & TWI \\
\hline Basic materials & 1 & 1 & (a) & 0 & (a) & (a) & 1 & (a) & 0 & (a) \\
Consumer goods & 0 & 0 & 0 & 0 & 0 & 0 & 0 & 0 & 0 & 0 \\
Consumer services & 1 & 1 & (a) & 0 & (a) & (a) & 0 & (a) & 0 & (a) \\
Financials & 0 & (a) & 0 & (a) & (a) & (a) & (a) & (a) & 0 & (a) \\
Health care & 0 & 1 & 0 & (a) & 1 & 1 & 0 & 1 & 0 & 0 \\
Industrials & (a) & (a) & (a) & 0 & (a) & (a) & (a) & (a) & (a) & (a) \\
Oil \& gas & (a) & (a) & (a) & 0 & (a) & (a) & (a) & 0 & 0 & (a) \\
Technology & 0 & 0 & 0 & 0 & 0 & 0 & 0 & 0 & 0 & 0 \\
Telecommunication & 0 & 0 & 0 & 0 & 0 & 0 & 0 & 0 & 0 & 0 \\
Utilities & 0 & 0 & 0 & 0 & 0 & 0 & 0 & 0 & 0 & 0 \\
\hline
\end{tabular}

Notes: 0 denotes no significant exposure, 1 denotes symmetric exposure, and (a) denotes asymmetric exposure. The $5 \%$ level of significance is adopted.

Table 4 presents the TWI exposure coefficient estimates for the 10 sector indices. The coefficient estimates of associated variance equation are not reported to conserve space. Similar to the market level analysis, the error terms in the variance equation are conditionally heteroskedasticity and the variance process is highly persistence. It is evident from Table 4 that domestic market return has a positive and dominant influence on all sector returns and the same results hold for the coefficient estimates of other currencies ${ }^{2}$. Of the six sectors with significant exposure, only the Basic Materials (with positive $\beta_{x}$ ) benefits from the appreciation of

\footnotetext{
${ }^{2}$ The results for exposure to other currencies are available from the author upon request.
} 
the Australian dollar and the asymmetric response (with negative $\beta_{D, x}$ ) is due to asymmetric hedging of foreign currency receivables or payables. The other five sectors, namely Consumer Services, Financials, Health Care, Industrials and Oil \& Gas (with negative $\beta_{x}$ ) would benefit from the depreciation of the Australian dollar. A positive $\beta_{D, x}$ estimate for these sectors suggests asymmetric pricing to market behavior as firms may adjust export prices to maintain market share during domestic currency appreciations (Knetter, 1994). Overall, the sign for the two coefficient estimates, $\beta_{x}$ and $\beta_{D, x}$, are similar for different currencies used in this study.

Table 4: TWI Exposure Coefficient Estimates for Sector Indices (January 1990 - June 2011)

\begin{tabular}{lcccc}
\hline Sector & $\beta_{1}$ & $\beta_{x}$ & $\beta_{D, x}$ & Adj. $R^{2}$ \\
\hline Basic materials & $0.9973^{*}$ & $0.2661^{*}$ & $-0.2031^{*}$ & 0.6102 \\
Consumer goods & $0.7296^{*}$ & -0.0814 & 0.0781 & 0.2087 \\
Consumer services & $0.9367^{*}$ & $-0.2479^{*}$ & $0.2094^{*}$ & 0.6286 \\
Financials & $0.9043^{*}$ & $-0.1317^{*}$ & $0.1590^{*}$ & 0.6902 \\
Health care & $0.7999^{*}$ & $-0.1390^{*}$ & -0.0306 & 0.4060 \\
Industrials & $0.8681^{*}$ & -0.0241 & $0.1785^{*}$ & 0.5475 \\
Oil \& gas & $0.9279^{*}$ & -0.2917 & $0.8287^{*}$ & 0.3974 \\
Technology & $0.7947^{*}$ & -0.1962 & 0.1916 & 0.1945 \\
Telecommunication & $0.6772^{*}$ & -0.1944 & 0.0628 & 0.1397 \\
Utilities & $0.5891^{*}$ & -0.0596 & 0.0484 & 0.1517 \\
\hline
\end{tabular}

Notes: $*$ denotes significant at the $5 \%$ level.

\section{CONCLUSION}

This study examines different currency exposure on market and 10 sector returns in Australia using weekly data over the January 1990 - June 2011 period. It provides important implications for investors and finance managers interested in the analysis of foreign exchange exposure, especially with the volatile exchange rate movement in recent time. On average, the Australian dollar has appreciated against the currencies of its major trading partners over the last two decades.

The evidence reported here is consistent with the findings in the international finance literature that support the significance of exchange rate risk on stock return. At the market level, significant exchange rate effects on Australian market returns are found for all five exchange rate series with asymmetric exposure to the Chinese yuan. At the sector level, domestic market return is found to have more significant influence than exchange rate risk on all sector returns. Of all 10 sectors, the four sectors that do not have any exchange rate exposure are Consumer Goods, Technology, Telecommunication and Utilities. The six sectors that have significant asymmetric exposure to at least one currency are Basic Materials, Consumer Services, Financials, Health Care, Industrials, and Oil \& Gas. Of the six sectors, Basic Materials would benefit from the appreciation of the Australian dollar while the other five sectors would benefit from the depreciation of domestic currency. The results also suggest the Chinese yuan exposure on the sector returns has increased in recent years.

It is important to note that the evidence provided above are subject to the estimation method used, particularly the assumption that returns and exchange risk are constant through time. Finally, future research should consider additional factors at both the firm and industry levels for a better understanding of the role and magnitude of the exchange rate influence on the firm value.

\section{ACKNOWLEDGMENT}

The author would like to acknowledge the contribution of Chien-Ting Lin in the development of this paper. 
Lim, Asymmetric foreign exchange exposure: a sector analysis

\section{REFERENCES}

Allayannis, G. (1996). Exchange rate exposure revisited, working paper, New York University.

Baillie, R.T. and T. Bollerslev. (1989). The message in daily exchange rates a conditional variance tail, Journal of Business and Economic statistics, 7, 297-305.

Bartov, E. and G.M. Bodnar. (1994). Firm valuation, earnings expectations, and the exchange-rate exposure effect, Journal of Finance, 49, 1755-86.

Berndt, E.K., H.B. Hall, R.E. Hall and J.A. Hausman. (1974). Estimation and inference in nonlinear structural models, Annals of Economic and Social Measurement, 4, 653-666.

Bodnar, G.M. and W.M. Gentry. (1993). Exchange-rate exposure and industry characteristics: Evidence from Canada, Japan and the U.S., Journal of International Money and Finance, 12, 29-45.

Bollerslev, T. (1986). Generalized autoregressive conditional heteroskedasticity, Journal of Econometrica, 31, 307-327.

Bollerslev,T., R.Y. Chou, and K. Kroner. (1992). ARCH modelling in finance: a review of the theory and empirical evidence, Journal of Econometrics, 52, 5-59.

Booth, L. (1996). On the nature of foreign exchange exposure, Journal of Multinational Financial Management, 6, 1-24.

Chamberlain, S., J.S. Howe, and H. Popper (1997). The exchange rate exposure of U.S. and Japanese banking institutions, Journal of Banking and Finance, 21, 871-889.

Chang, Y.C. (2002). The pricing of foreign exchange rate risk around the Asian financial crisis: Evidence from Taiwan's stock market, Journal of Multinational Financial Management, 12, 223-238.

Chow, E., W. Lee, and M. Solt (1997). The economic exposure of US multinational firms, Journal of Financial Research, 20, 191-210.

Christophe, S.E. (1997). Hysteresis and the value of the U.S. multinational corporations, Journal of Business, $70,435-462$.

Dickey, D.A. and W.A. Fuller (1981). Likelihood ratio tests for autoregressive time series with a unit root, Econometrica, 49, 1057-1072.

Di Iorio, A. and R. Faff (2000). An analysis of asymmetry in foreign currency exposure of the Australian equities market, Journal of Multinational Financial Management, 10, 133-159.

Froot, K.A. and P.D. Klemperer (1989). Exchange rate pass-through when market share matters, Economic Review, 79, 637-654.

Griffin, J.M. and R.M. Stulz (2001). International competition and exchange rate shocks: A cross-country industry analysis of stock returns, Review of Financial Studies, 14, 215-241.

He J. and L. Ng (1998). The foreign exchange exposure of Japanese multinational corporations, Journal of Finance, 53, 733-753.

Hsieh, D.A. (1989). Modelling heteroskedasticity in daily foreign exchange rates, Journal of Business and Economic Statistics, 7, 307-317.

Jarque, C.M. and A.K. Bera. (1980). Efficient tests for normality, homoscedasticity and serial independence of regression residual, Economic Letters, 6, 225-229.

Jorion, P. (1990). The exchange rate exposure of U.S. multinationals, Journal of Business, 63, 331-345.

Jorion, P. (1991). The pricing of exchange rate risk in the stock market, Journal of Financial and Quantitative Analysis, 26, 363-376.

Khoo, A. (1994). Estimation of Foreign exchange exposure - an application to mining companies in Australia, Journal of International Money and Finance, 13, 342-363.

Knetter, M.M. (1994). Is export price adjustment asymmetric?: evaluating the market share and marketing bottlenecks hypotheses, Journal of International Money and Finance, 13, 55-70.

Koutmos, G. and A.D. Martin (2003). Asymmetric exchange rate exposure: theory and evidence, Journal of International Money and Finance, 22, 365-383.

Ljungqvist, L. (1994). Hysteresis in international trade: a general equilibrium analysis, Journal of International Money and Finance, 13, 387-399.

Marston, R.C. (1990). Pricing to market to Japanese manufacturing, Journal of International Economics, 29, 217-236.

Meese, R.A. and K. Rogoff (1982). On unit roots and the empirical modelling of exchange rates, Journal of Finance, 37, 1029-1035.

Phillips, P.C. B. and P. Perron (1988). Testing for a unit root in time series regression, Biometrica, 75, 335346.

RBA (2011), Statistics on the Reserve Bank of Australia website. Retrieved on 30 September 2011, from http://www.rba.gov.au/statistics/frequency/twi.html. 